\title{
KEMAMPUAN TEKNIK DASAR BOLA BASKET: STUDI DESKRIPTIF PADA MAHASISWA
}

\author{
Arief Abdul Malik ${ }^{1)}$, dan Iman Rubiana ${ }^{2)}$ \\ ${ }^{12}$ Pendidikan Jasmani, Fakultas Keguruan dan Ilmu Pendidikan, Universitas Siliwangi \\ e-mail: arief.abdulmalik@unsil.ac.id ${ }^{1}$,imanrubiana@ unsil.ac.id ${ }^{2}$,
}

\begin{abstract}
Abstrak
Pada tahun 2019 merupakan tahun pertama seleksi bersama masuk perguruan tinggi negeri (SBMPTN) menggunakan portofolio bagi mahasiswa yang memilih program studi dalam bidang seni dan/atau olahraga. Tujuan dari penelitian ini adalah untuk mengetahui kemampuan teknik dasar bola basket pada mahasiswa pendidikan jasmani yang masuk melalui jalur SBMPTN pada tahun 2019. Penelitian ini merupakan penelitian deskriptif dengan sampel sebanyak 130 mahasiswa yang berusia 17-21 tahun. Instrumen yang digunakan adalah tes passing ke dinding dengan jarak 3 meter selama 30 detik, tes shooting selama 30 detik, dan tes menggiring bola dengan zig zag. Data dianalisis dengan menggunakan teknik statistik deskriptif. Dari hasil penelitian diperoleh infomasi bahwa rata-rata kemampuan teknik dasar bola basket mahasiswa berada pada kategori cukup berdasarkan penilaian acuan nilai (PAN). Perlu adanya perbandingan antara penerimaan mahasiswa melalui jalur lain agar dapat diketahui perbedaan kemampuan mahasiswa pada masing-masing jalur penerimaan berdasarkan cabang olahraga yang diajarkan pada jurusan yang memiliki program studi olahraga agar didapatkan data yang lebih komprehensif.
\end{abstract}

Kata Kunci : Bola basket, Teknik Dasar, Mahasiswa, SBMPTN

\begin{abstract}
In 2019 is the first year of joint selection of entering state universities (SBMPTN) using a portfolio for students who choose courses in the arts and/or sports. The purpose of this study was to determine the basic technical abilities of basketball in physical education students who entered through the SBMPTN pathway in 2019. This research was a descriptive study with a sample of 130 students aged 17-21 years. The instrument used was a passing test to the wall with a distance of 3 meters for 30 seconds, a shooting test for 30 seconds, and a dribbling test with zig zag. Data were analyzed using descriptive statistical techniques. The results of the study obtained information that the average ability of a student's basic basketball technique is in a sufficient category based on the assessment of the reference value (PAN). There needs to be a comparison between student admissions through other student admission paths so that differences in students' abilities in each admission path can be known based on sports taught in majors that have sports studies programs to obtain more comprehensive data.
\end{abstract}

Keywords: Basketball, Basic technique, College student, SBMPTN 


\section{Pendahuluan}

Bola basket merupakan permainan tim dengan karakteristik olahraga aerobic-based anaerobic (Alemdaro, 2012; Delextrat \& Cohen, 2009) dan memerlukan intensitas gerak yang tinggi seperti berlari, berhenti, dan melakukan gerakan berpindah sesuai dengan situasi dalam permainan (Kong, Qi, \& Shi, 2015). Penguasaan kemampuan teknik dasar menjadi penting untuk dimiliki setiap pemain selain kemampuan taktik dalam permainan sehingga performa bermain dapat berjalan dengan baik (Erčulj, Blas, \& Bračič, 2010). Sama halnya dalam permaian dan pertandingan, teknik dasar yang dimiliki seseorang merupakan modal awal yang penting untuk diketahui dalam proses pembelajaran. Ketika kemampuan dasar awal diketahui maka pelatih atau pengajar dapat memberikan formulasi dan metode yang tepat agar target capaian pembelajaran maupun latihan terpenuhi.

Penelitian studi deskriptif telah banyak digunakan dan berguna untuk mengetahui gambaran teknik dasar pemain dan persentase penggunaannya ketika pertandingan olahraga. Pada penelitian cabang olahraga bola basket, Devita (2013) mengungkapkan bahwa rata-rata kemampuan teknik dasar bermain bolabasket (passing, dribbling dan shooting) pada KU 18 Putra Klub Sahabat Semarang tahun 2012 berada pada kategori cukup. Pada cabang olahraga sepak bola diperoleh informasi bahwa dari 3 pertandingan yang dilakukan klub Sinar Harapan, Tulangan Sidoarjo pada Kompetisi Liga 3 Regional Jatim, teknik dasar yang paling dominan dipakai selama pertandingan adalah teknik dasar mengoper dengan rata-rata sebesar 203 kali dengan prosentase $63,43 \%$ (Febrianto, 2017).

Pada tahun 2019, untuk pertama kalinya seleksi bersama masuk perguruan tinggi negeri (SBMPTN) bagi mahasiswa yang memilih program studi dalam bidang seni dan/atau olahraga menggunakan tes portofolio. Adapun bentuk penilaian tes portofolio yang dikutip dari website resmi SBMPTN yaitu data informasi kesehatan, data keterampilan motorik dan tambahan data prestasi serta rekaman profil individu dan rekaman penampilan terbaik peserta dalam salah satu cabang olahraga (SBMPTN, 2019). Seleksi masuk dengan tes portofolio mendapatkan tanggapan dan beberapa rekomendasi yang terwujud dalam pertemuan Dekan Keolahragaan se-Indonesia yang berlangsung pada tanggal 30 November sampai 02 Desember 2018 yang mengungkapkan bahwa seleksi keterampilan perlu dan penting untuk tetap dilaksanakan guna mencari potensi dan kualifikasi para calon mahasiswa karena sistem portofolio yang mempercayakan sekolah dan pengalaman kejuaraan untuk melihat prestasi di bidang olahraga belum bisa menunjukkan potensi maksimal setiap calon mahasiswa baru (Maba). Lebih lanjut tes keterampilan merupakan modal awal yang dimiliki calon mahasiswa (Redaksi Unesa, 2018).

Penguasaan teknik dasar pada cabang olahraga bola basket diperlukan agar memudahkan mahasiswa ketika mengikuti proses pembelajaran. Disamping itu, ketika diterapkan dalam permainan atau simulasi pertandingan penguasaan teknik dasar yang baik dapat berpengaruh pada pergerakan yang dilakukan menjadi efektif dan efisien. Oleh karena itu, kemampuan teknik 
dasar bola basket sangat diperlukan untuk diketahui sebagai gambaran awal tentang kemampuan mahasiswa khususnya jalur penerimaan SBMPTN dalam mengikuti pembelajaran bola basket. Hal ini dapat membantu pengajar dalam mengidentifikasi kekurangan dan kelebihan mahasiswa sehingga proses pembelajaran nantinya dapat berjalan lebih efektif dengan penerapan model pembelajaran yang tepat.

\section{METODE}

Penelitian ini merupakan jenis penelitian deskriptif yaitu penelitian yang dilakukan tanpa memberikan perlakuan atau treatmen pada suatu kelompok, akan tetapi hanya melihat fenomena atau gambaran yang terjadi pada kelompok tersebut (Maksum, 2018).

Partisipan yang terlibat dalam penelitian ini adalah mahasiswa pendidikan jasmani yang masuk melalui jalur penerimaan SBMPTN pada tahun 2019 dengan jumlah 130 mahasiswa berusia 17-21 tahun dengan rincian 103 laki-laki dan 27 perempuan.

Instrumen yang digunakan dalam penelitian ini terdiri dari 3 item tes yaitu pertama tes passing ke dinding dengan jarak 3 meter selama 30 detik, kedua tes shooting berupa under ring selama 30 detik dan ketiga tes kecepatan dribbling zig zag. Selanjutnya data dianalisis dengan menggunakan teknik deskriptif statistik menggunakan kategori PAN atau penilaian acuan nilai (Nurhasan \& Narlan, 2007) dengan rincian kategori seperti yang tertera pada tabel 1

Tabel 1. Kategori Penilaian Acuan Nilai (PAN)

\begin{tabular}{cc}
\hline Rumus Nilai & Kategori Penilaian \\
\hline $\bar{X}+\mathbf{3}(\mathrm{SD})$ & Baik Sekali \\
\hline $\bar{X}+\mathbf{1 . 8}(\mathrm{SD})$ & Baik \\
\hline $\bar{X}+\mathbf{0 . 6}(\mathrm{SD})$ & Cukup \\
\hline $\bar{X}-\mathbf{0 . 6}(\mathrm{SD})$ & Kurang \\
\hline $\bar{X}-\mathbf{1 . 8}(\mathrm{SD})$ & Kurang Sekali \\
\hline $\bar{X}-\mathbf{3}$ (SD) &
\end{tabular}

\section{HaSil dan PeMbahasan}

Penelitian ini bertujuan untuk menggambarkan kemampuan teknik dasar mahasiswa jalur penerimaan SBMPTN dilihat dari cabang olahraga bola basket.

Data penelitian yang dilakukan menggambarkan hasil kemampuan teknik dasar bola basket meliputi kemampuan passing, dribbling dan shooting. Adapun ringkasan deskriptif data hasil penelitian secara keseluruhan adalah sebagai berikut:

Tabel 2. Ringkasan Deskripsi Data Kemampuan Teknik Dasar Bola basket

\begin{tabular}{lccc}
\hline & Passing & Dribbling & Shooting \\
\hline Jumlah & 2975 & 3171.11 & 894 \\
\hline Rerata & 22.88 & 24.39 & 6.93 \\
\hline Min & 11 & 17.73 & 1 \\
\hline Max & 33 & 37.13 & 14 \\
\hline SD & 4.35 & 3.44 & 2.92 \\
\hline
\end{tabular}

Dari tabel 2 terlihat bahwa rerata skor passing adalah 22.88 poin, dribbling 24.39 detik, dan shooting 6.93 poin. Skor minimal yang diperoleh pada kemampuan passing, dribbling, dan shooting secara berurut adalah adalah 11 poin, 17.73 detik dan 1 poin. Sedangkan skor maksimal yang diperoleh pada kemampuan passing adalah 33 poin, dribbling adalah 37.13 detik, dan shooting 14 poin. Sebagai informasi tambahan bahwa semakin tinggi poin passing dan shooting yang 
didapatkan maka semakin bagus kategori penilaian, sedangkan semakin cepat atau semakin sedikit waktu yang diperlukan ketika melakukan dribbling maka semakin bagus kategori penilaiannya. Secaca terperinci, grafik kategori kemampuan teknik dasar bola basket mahasiswa ditunjukkan pada gambar 1, 2, dan 3 .

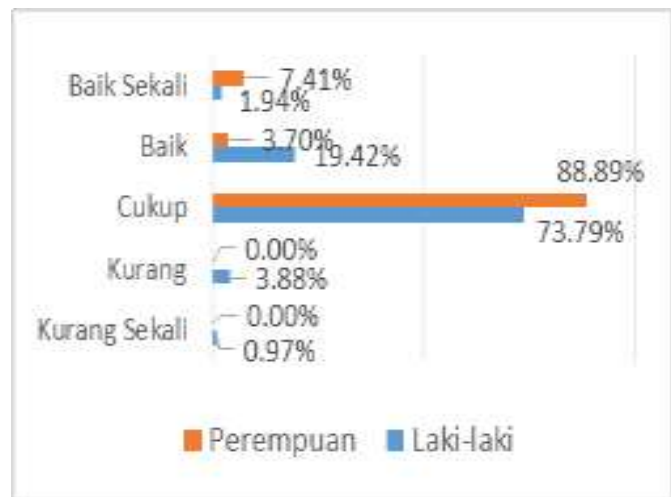

Gambar 1. Persentase Hasil Passing Bola Basket

Pada gambar 1 terlihat persentase hasil passing bola basket pada mahasiswa laki-laki dan perempuan. Capaian tertinggi pada kategori cukup untuk perempuan dengan persentase hasil sebesar $88.89 \%$ dan pada lakilaki persentase cukup sebesar $73.79 \%$ sedangkan capaian terendah pada kategori kurang dan kurang sekali pada perempuan yaitu $0 \%$ dan kategori kurang sekali pada laki-laki yaitu sebesar $0.97 \%$.

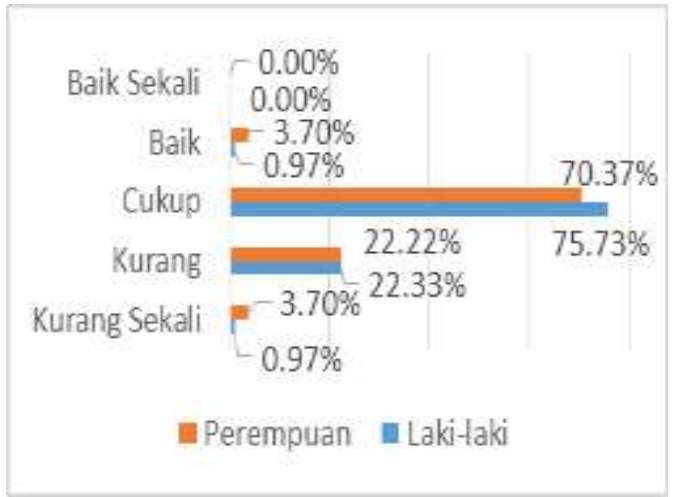

Gambar 2. Persentase Hasil Dribling Bola Basket

Pada gambar 2 menunjukkan persentase hasil dribbling bola basket pada mahasiswa laki-laki dan perempuan. Kategori cukup mendapatkan persentase tertinggi baik untuk laki-laki dengan capaian $75.73 \%$ maupun pada perempuan dengan capaian persentase $70.37 \%$. Selanjutnya capaian terendah ditunjukkan pada kategori baik sekali dengan persentase $0 \%$ untuk laki-laki dan perempuan.

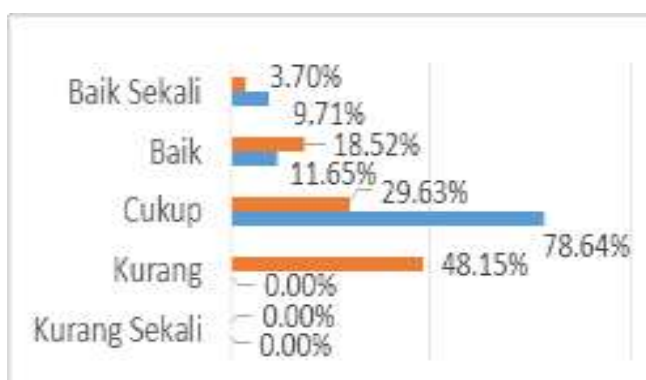

- Perempuan = Laki-laki

\section{Gambar 3. Persentase Hasil Shooting} Bola Basket

Persentase hasil shooting bola basket pada mahasiswa laki-laki dan perempuan terlihat pada gambar 3 . Capaian tertinggi pada laki-laki berada pada kategori cukup dengan persentase 78.64\% sedangkan capaian tertinggi perempuan pada kategori kurang dengan persentase $48.15 \%$. Capaian terendah ditunjukkan pada kategori kurang sekali dengan persentase $0 \%$ untuk laki-laki dan perempuan.

Permainan bola basket merupakan permainan yang komplek, artinya diperlukan kemampuan teknik dan pemahaman taktik yang menyeluruh dalam bermain (Erčulj et al., 2010). Teknik dalam permainan bola basket dapat diartikan sebagai suatu cara yang efektif dan efisien dalam memainkan 
bola sesuai dengan peraturan permainan yang berlaku guna mencapai hasil yang optimal. Lebih lanjut, penguasaan berbagai teknik dasar yang tepat memungkinkan pemain dalam menampilkan permainan yang baik (Hapsari, Pratiknyo, \& Hidayah, 2013).

\section{KESIMPULAN DAN SARAN}

Pada penelitian ini, peneliti hanya mengungkap keterampilan mahasiswa jalur penerimaan SBMPTN dilihat dari sisi keterampilan teknik dasar olahraga bola basket dengan kategori penilaian acuan nilai (PAN). Hasil rata-rata kemampuan teknik dasar bola basket meliputi kemampuan passing, dribbling dan shooting pada mahasiswa jalur penerimaan SBMPTN berada pada kategori cukup pada mahasiswa laki-laki dan perempuan, hanya hasil shooting pada perempun berada pada kategori kurang.

Pada penelitian selanjutnya, tidak menutup kemungkinan bagi penelitian sejenis untuk menelitinya dalam cabang olahraga yang lain atau dapat dibandingkan dengan mahasiswa dari penerimaan jalur lain seperti Seleksi Nasional Masuk Perguruan Tinggi Negeri (SNMPTN) dan seleksi mandiri agar memperoleh gambaran hasil yang lebih komprehensif.

\section{DAFTar Pustaka}

Alemdaro, U. (2012). The Relationship Between Muscle Strength, Anaerobic Performance, Agility, Sprint Ability and Vertical Jump Performance in Professional Basketball Players. Journal of Human Kinetics, 31, 149-158. https://doi.org/10.2478/v10078012-0016-6
Delextrat, A., \& Cohen, D. (2009). Strength, Power, Speed, and Agility of Women Basketball Players According to Playing Position. Journal of Strength and Conditioning Research, 23(7), 1974-1981.

https://doi.org/10.1519/jsc.0b013e $3181 \mathrm{~b} 86 \mathrm{a} 7 \mathrm{e}$

Devita, A. (2013). Survey Tes Tingkat

Kemampuan Teknik Dasar

Bermain Bola Basket (Passing, Dribbling, dan Shooting) Pada Tim Bola Basket Putra Kelompok Umur 18 Tahun Klub Sahabat Semarang Tahun 2012. Universitas Negeri Semarang.

Erčulj, F., Blas, M., \& Bračič, M. (2010). Physical Demands on Young Elite European Female Basketball Players With Special Reference to Speed, Agility, Explosive Strength, and Take-off Power. Journal of Strength and Conditioning Research, 24(11), 2970-2978.

https://doi.org/10.1519/jsc.0b013e 3181e38107

Febrianto, F. (2017). Analisis Teknik Dasar Permainan Sepakbola Klub Sinar Harapan Tulangan Sidoarjo Pada Liga 3 Regional Jatim. Jurnal Prestasi Olahraga, 2(1).

Hapsari, A., Pratiknyo, E., \& Hidayah, T. (2013). Status Ketrampilan Bermain Bola Basket Pada Club NBC (Ngaliyan Basketball Center) Kota Semarang. Journal of Sport Sciences and Fitness, 2(1), 6-10.

Kong, Z., Qi, F., \& Shi, Q. (2015). The influence of basketball dribbling on repeated high-intensity intermittent runs. Journal of Exercise Science \& Fitness, 13(2), 117-122. https://doi.org/10.1016/j.jesf.2015 
.10 .001

Maksum, A. (2018). Metode Penelitian dalam olahraga. Surabaya: Unesa University Press.

Nurhasan, \& Narlan, A. (2007). Tes dan pengukuran Olahraga. Tasikmalaya: Universitas Siliwangi.

Redaksi Unesa. (2018). Kebijakan Baru SBMPTN 2019, Dekan Keolahragaan se-Indonesia Gelar Pertemuan di Unesa. Retrieved from https://www.unesa.ac.id/kebijakan -baru-sbmptn-2019-dekankeolahragaan-se-indonesia-gelarpertemuan-di-unesa (diakses 12 Desember 2019)

SBMPTN. (2019). Laman Resmi Seleksi Bersama Masuk Perguruan Tinggi Negeri Tahun 2019. Retrieved from https://sbmptn.ltmpt.ac.id/?mid=1 3 (diakses 12 Desember 2019) 